Research Article

\title{
Solid-Liquid Separation Properties of Thermoregulated Dicationic Ionic Liquid as Extractant of Dyes from Aqueous Solution
}

\author{
Rui Lv (D), Shuya Cui $(\mathbb{D}$, Yangmei Zou, and Li Zheng \\ Department of Chemistry and Chemical Engineering, Mianyang Teacher's College, Mianyang, Sichuan 621000, China \\ Correspondence should be addressed to Shuya Cui; cuishuya@hotmail.com
}

Received 27 March 2018; Accepted 29 April 2018; Published 3 June 2018

Academic Editor: Ricardo Jorgensen Cassella

Copyright (C) 2018 Rui Lv et al. This is an open access article distributed under the Creative Commons Attribution License, which permits unrestricted use, distribution, and reproduction in any medium, provided the original work is properly cited.

\begin{abstract}
Two thermoregulated dicationic ionic liquids were synthesized and applied for effective extraction of the common dye malachite green oxalate (MG). The extraction parameters such as amount of ionic liquids, $\mathrm{pH}$ of water phase, extraction time, cooling time, and centrifugal time on the extraction efficiency were investigated systematically. It revealed that the dye has been successfully extracted into the ionic liquids, with high extraction efficiency higher than $98 \%$, and recovery of $98.2 \%-100.8 \%$, respectively. Furthermore, these ionic liquids can be recycled easily after elution. The reusable yields were $87.1 \%$ and $88.7 \%$. The extraction of the dye into the thermoregulated ionic liquid provides a method of minimizing pollution of waste water potentially.
\end{abstract}

\section{Introduction}

Ionic liquid is a widely used extraction solvent, because of its high heat stability, vapor pressure, nonvolatility, and friendly environment perception [1]. In recent years, there are many researches about ionic liquid as an extractant for dye from various samples such as Congo red, Sudan dye, methyl orange, and so on [2-4], but the application of ionic liquids is restrained due to its high cost and hard to recycle $[5,6]$.

Thermoregulated ionic liquids are a kind of ionic liquids, with appearing liquid phase at high temperatures and solid phase at low temperatures [7]. They can be used to achieve separation and enrichment of the target compounds by changing the temperature. Further, based on the advantages, it can be easily recycled. In recent years, the reports about using temperature-sensitive ionic liquids as extractant have been mostly concentrated in the area of metal ions $[8,9]$, but rarely involved in dyes.

Malachite green (MG), which is one of the triphenylmethane dyes, is widely used in aquaculture to prevent fungal infections and kill parasites due to its low price. However, it was found that malachite green had potential carcinogenic, teratogenic, and mutagenic effects [10]. So, it was banned to use in aquaculture in several countries in the world [11]. Therefore, separation and determination of malachite green in water is very important to human health.

As the residues of malachite green in water are low, the efficient enrichment method is needed. Common methods of separation and enrichment are physical adsorption $[12,13]$, liquid-liquid extraction [14, 15], and solid-phase extraction (SPE) $[16,17]$. These methods have lots of disadvantages to limit their application because they are expensive or use organic solvent which may lead to environmental pollution. Therefore, looking for a simple, efficient green method becomes necessary.

In this study, two thermoregulated ionic liquids with hydrophobic properties were synthesized and employed to separate and concentrate malachite green in water. Some parameters which would influence the separation process were investigated, and the optimum condition was obtained. Further, the feasibility of the method was validated by analyzing the real water sample and simulation water sample. The efficient, simple, and environmental friendly method was confirmed to be useful to separate and enrich the malachite green in water. 


\section{Materials and Methods}

2.1. Chemicals. Standard malachite green was supplied by the National Research Center for Reference Material (Beijing, China). N-methylimidazole (>99\%) and $\mathrm{KPF}_{6}(>99 \%)$ were purchased from Shanghai Aladdin Reagent Co., Ltd. (Shanghai, China). Thionyl chloride, diethylene glycol, triethylene glycol, $\mathrm{Na}_{2} \mathrm{HPO}_{4}$, and $\mathrm{NaH}_{2} \mathrm{PO}_{4}$ were all of analytical grade and brought from Chengdu Kelong Reagent Co., Ltd. (Sichuan, China).

2.2. Apparatus. The melting point of ionic liquid was tested by XT-4 melting point meter (Beijing Tech Instrument Co., Ltd.) at room temperature with the thermometer uncorrected. ${ }^{1} \mathrm{H}$ NMR and ${ }^{13} \mathrm{C}$ NMR spectra were recorded on $600 \mathrm{MHz}$ NMR spectrometer (Varian, USA) with the solvent of acetone-d. FTIR spectra were registered on IRAffinity-1S FTIR spectrometer (Shimadzu, Japan). UV-visible spectra were obtained from a T6 UV-visible spectrophotometer (Beijing Persee, China) at the maximum absorption wavelength of $616.9 \mathrm{~nm}$. TG16-W high-speed centrifugation (Hunan Xiangyi Laboratory Instrument Development Co., Ltd., China) was employed to accelerate the phase separation process. The temperature was controlled by HH-6 thermostatic water bath (Changzhou Jintan Liangyou Instrument Co., Ltd., China). The $\mathrm{pH}$ of the extraction system was measured with PHSJ-3F pH meter (Shanghai Inesa Analytical Instrument Co., Ltd., China).

2.3. Water Sample Collection. Water samples were collected from fish ponds in Mianyang, China. All the water samples were filtered through $0.45 \mu \mathrm{m}$ microporous membrane filter before extraction.

2.4. Preparation of Ionic Liquids. With diethylene glycolbridged functionalized imidazolium dicationic ionic liquids as an example, synthesis route of polyethylene glycolbridged functionalized imidazolium dicationic ionic liquids was shown in four steps as follows: Firstly, thionyl chloride was added to diethylene glycol in anhydrous environment and then heated to $250^{\circ} \mathrm{C}$ until no starting material was observed using TLC. And then, it was cooled and extracted with $\mathrm{CHCl}_{2}$. The extract was washed with water, saturated $\mathrm{NaHCO}_{3}$ solution, and saturated $\mathrm{NaCl}$ solution. The product is dried under reduced pressure. Secondly, $\mathrm{N}$-methylimidazole was added to the above dichlorodiglycol in methanol at room temperature. The reaction continued for $24 \mathrm{~h}$. The solvent was removed under reduced pressure to yield a viscous gum and soluble in water and in methanol. The obtained dichloride salt was used directly, without further purification. Then, the obtained dichloride salt was dissolved in methanol, and then, $\mathrm{KPF}_{6}$ was added with rapid stirring. After four hours, the solvent was removed under reduced pressure. The residue was washed by water and filtrated to collect the solid. The solid was recrystallized in acetone and the colorless crystal generated, named IL-1 and 2IL-2. For IL-1, the yield was $90 \%$. m.p.: $91-93^{\circ} \mathrm{C}$. IR ( $\nu \max$,

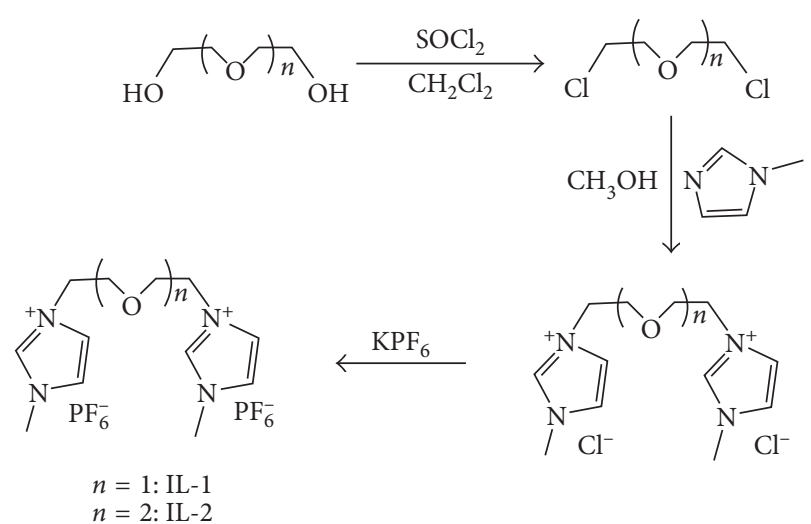

FIGURE 1: Synthesis route of two thermoregulated dicationic ionic liquids.

$\left.\mathrm{KBr}, \mathrm{cm}^{-1}\right): 3174,2916,1627,1577,1460,1324,1161,850$, 557. ${ }^{1} \mathrm{H}$ NMR $\left(600 \mathrm{MHz}, \mathrm{CD}_{3} \mathrm{COCD}_{3}, \delta, \mathrm{ppm}\right): 3.97$ (s, $6 \mathrm{H}$, $\left.\mathrm{N}-\mathrm{CH}_{3}\right), 4.05\left(4 \mathrm{H}, \mathrm{s}, \mathrm{N}-\mathrm{CH}_{2}\right), 4.32\left(4 \mathrm{H}, \mathrm{s}, \mathrm{O}-\mathrm{CH}_{2}\right), 7.68$ $(4 \mathrm{H}, \mathrm{C}(4,5)-\mathrm{H}), 9.03(2 \mathrm{H}, \mathrm{C}(2)-\mathrm{H}) ;{ }^{13} \mathrm{C}$ NMR $(150 \mathrm{MHz}$, $\left.\mathrm{CD}_{3} \mathrm{COCD}_{3}, \delta, \mathrm{ppm}\right): 136.7$ (C-2), 124.5, 124.0 (C-4,5), 69.5 $\left(\mathrm{O}-\mathrm{CH}_{2}\right), 50.3\left(\mathrm{~N}-\mathrm{CH}_{2}\right)$, and $36.6\left(\mathrm{~N}-\mathrm{CH}_{3}\right)$. The structure of IL-2 was consistent with the data reported by the previous literature [18].

The synthesis route and structures of these two thermoregulated dicationic ionic liquids are shown in Figure 1.

2.5. Preparation of Standard Solution. A stock solution of malachite green (0.5 wt.\%) was prepared by dissolving in distilled water. Other concentrations of the sample solution were prepared by diluting the stock solution with distilled water.

2.6. Experimental Methods. The extraction experiment was carried out in the sample solution with two ionic liquids (IL-1 and IL-2) as extractants, respectively. Firstly, mix the sample solution and ionic liquid and heat the mixture solution to make the ionic liquid melt and distribute in the sample solution for extraction $\left(90^{\circ} \mathrm{C}\right.$ for IL- 1 solution and $60^{\circ} \mathrm{C}$ for IL2 ). After that, the mixture was cooled to room temperature while the IL was separated. Finally, the mixture was centrifuged at $3000 \mathrm{r} / \mathrm{min}$ to get the supernatants, and the concentration of dye was measured using UV spectrophotometer $(616.9 \mathrm{~nm})$. The extraction ratio can be calculated by the following equation:

$$
R(\%)=\frac{\left(C_{0}-C_{1}\right) V_{\mathrm{aq}}}{C_{0} V_{\mathrm{aq}}} \times 100 \%,
$$

where $C_{0}$ represents the concentration of malachite green in the sample solution, $C_{1}$ refers to the concentration of malachite green in supernatants after extraction, and $V_{\text {aq }}$ is the volume of the extraction phase. $C_{1}$ was obtained by standard curve calculation.

\section{Results and Discussion}

3.1. Effect of the Amount of Ionic Liquids. The amount of extractive agent was an important parameter for sample 


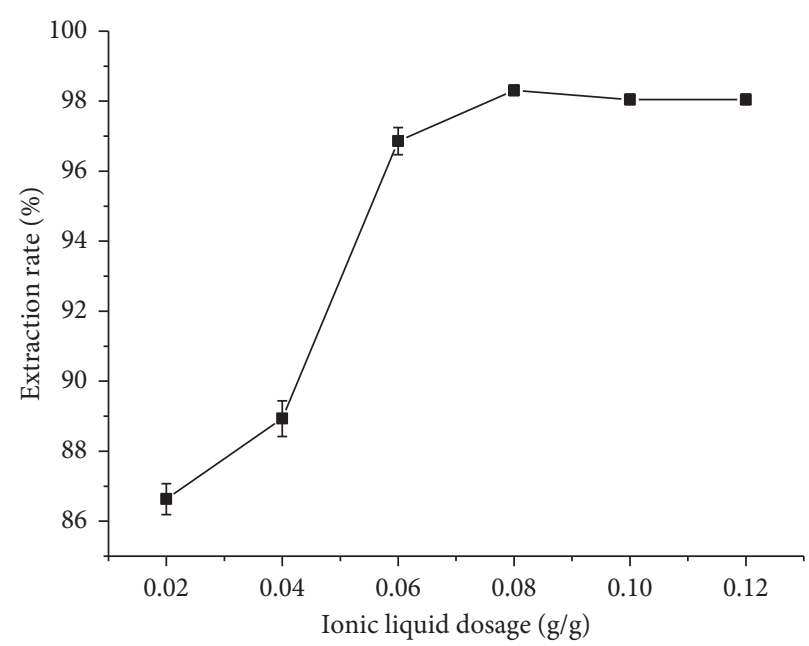

(a)

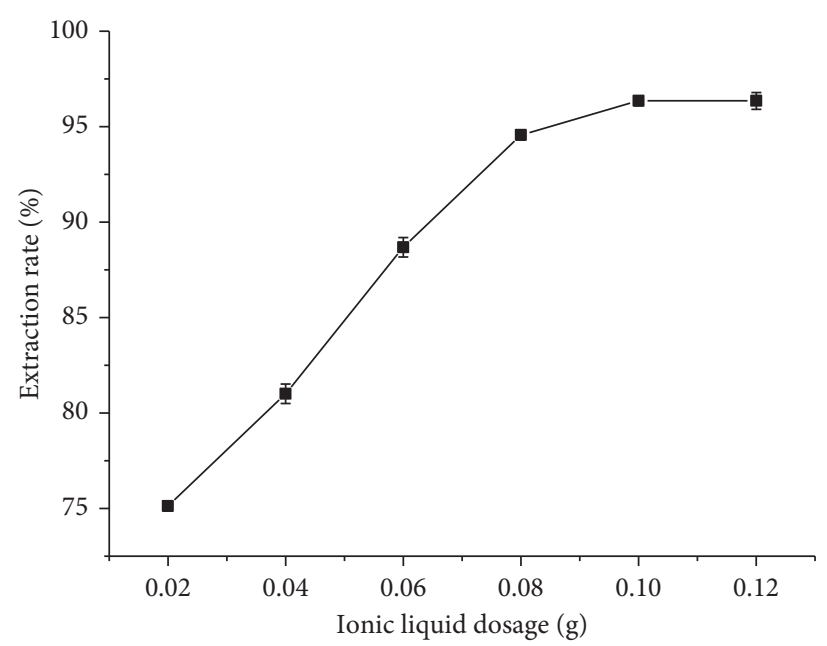

(b)

Figure 2: Effect of the amount of ionic liquids on extraction rate. (a) IL-1; (b) IL-2. The error bars represent the standard deviation of measurements in three parallel experiments $(n=3)$.

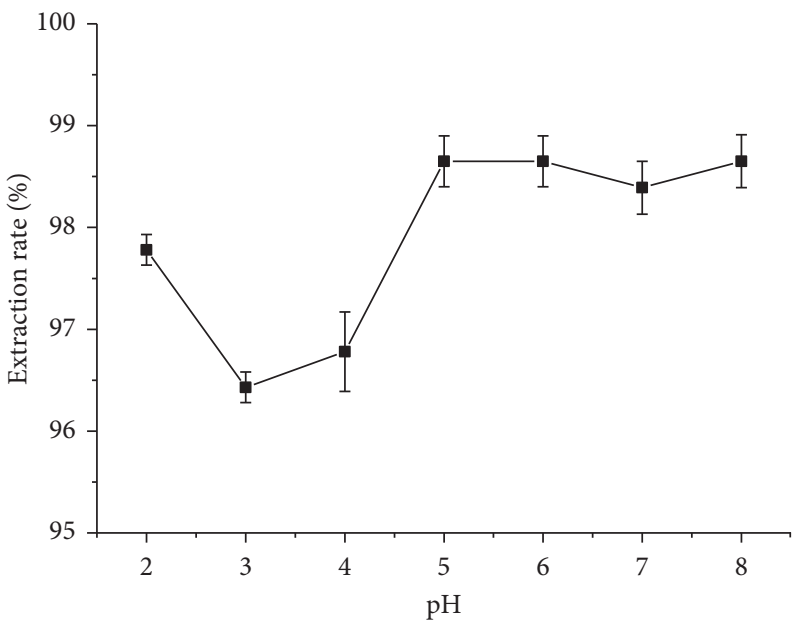

(a)

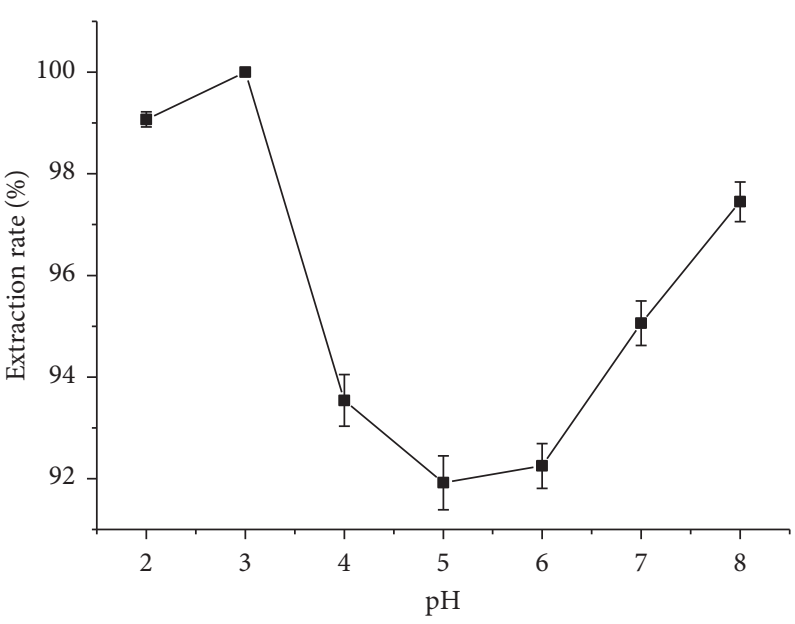

(b)

Figure 3: Effect of the pH on extraction rate. (a) IL-1; (b) IL-2. The error bars represent the standard deviation of measurements in three parallel experiments $(n=3)$.

extraction efficiency. The effect of the amount of ionic liquid on the extraction rate was examined and the result was shown in Figure 2. It was found that the extraction rate reached the maximum of $98.39 \%$ when the weight of IL-1 increased to $0.0800 \mathrm{~g}$, while the maximum extraction rate was $96.35 \%$ when the IL- 2 was $0.1000 \mathrm{~g}$. Therefore, $0.0800 \mathrm{~g}$ IL-1 and $0.1000 \mathrm{~g}$ IL-2 were chosen, respectively, for the following experiments.

3.2. Effect of $p H$. The structure of malachite green varied with $\mathrm{pH}$ in solution, which affected the extraction rate of ionic liquids. Phosphate buffer was applied to control $\mathrm{pH}$ values. The effect of $\mathrm{pH}$ on the extraction rate was determined (Figure 3 ). Results showed that the extraction rate was varying slightly with $\mathrm{pH}$ when IL-1 was employed as the extractant; by comparison, when IL-2 was employed as the extractant, the extraction rate first increased and then decreased with the increase in $\mathrm{pH}$. But both of them can obtain the optimum extraction efficiency in the acidic solution. It may be because the $\mathrm{pKa}$ of $\mathrm{MG}$ is 6.9; when the $\mathrm{pH}$ was lower than it, the MG presents in its molecular state, which may help in extraction. But owing to the different molecular space conformation in the two ILs, they may have different effects depending on the $\mathrm{pH}$ value. Therefore, $\mathrm{pH} 5$ was chosen as the optimal $\mathrm{pH}$ for IL-1, and $\mathrm{pH} 3$ was chosen as the optimal $\mathrm{pH}$ for IL-2.

3.3. Effect of Extraction Time. Ionic liquids show the liquid state when the extraction temperature was set above their melting point. Under this temperature, the target compounds in water can be extracted. Therefore, in this study, the extraction temperature was set at $90^{\circ} \mathrm{C}$ for IL-1, while it 


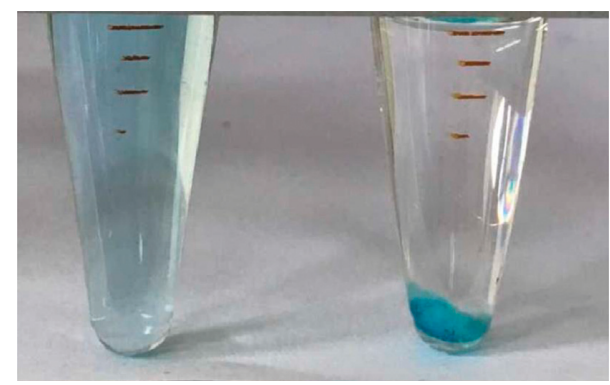

FIgURE 4: The ionic liquid at extraction stage and separation stage.

was set at $60^{\circ} \mathrm{C}$ for IL-2, respectively, to investigate the effects of extraction time (2-12 min with $2 \mathrm{~min}$ interval) on the extraction rate. From the results, it was found that when IL-1 was used as an extraction agent, the extraction rate reached the maximum when the extraction time was $4 \mathrm{~min}$. At the same time, when IL-2 was used as an extraction agent, the extraction rate can reach $100 \%$ when the time was $1 \mathrm{~min}$.

3.4. Effect of Cooling Time. For thermoregulated ionic liquid, when the temperature is below its melting point, it will be a hydrophobic solid precipitation, and cooling time determines the amount of precipitation. So, the effect of cooling time (1-11 min with 2 min interval) on extraction was studied. The experiment results showed that when the cooling time was $3 \mathrm{~min}$ for IL-1 and $7 \mathrm{~min}$ for IL-2, it reached the maximum extraction rate.

3.5. Effect of Centrifugal Time. The centrifugal process is to separate the solid extraction reagent and sample solution. The effect of centrifugal time (5-15 min with 5 min interval) on the extraction rate was investigated. It was found that when centrifuged at $3000 \mathrm{r} / \mathrm{min}$ for $5 \mathrm{~min}$, the extraction rate reached the maximum.

In summary, the optimum condition for IL-1 was as follows: $0.0800 \mathrm{~g} \mathrm{IL}$, buffer $\mathrm{pH} \mathrm{5}$, extraction time $4 \mathrm{~min}$, cooling time $3 \mathrm{~min}$, and centrifugation at $3000 \mathrm{r} / \mathrm{min}$ for $5 \mathrm{~min}$, and the optimum condition for IL- 2 was $0.1000 \mathrm{~g}, \mathrm{pH} 3$, extraction time $1 \mathrm{~min}$, cooling time $7 \mathrm{~min}$, and centrifugation time $5 \mathrm{~min}$ at $3000 \mathrm{r} / \mathrm{min}$. Under the optimum conditions, the extraction rate of malachite green was $98.90 \%$ and $100 \%$ by using IL-1 and IL-2, respectively. Figure 4 shows the ionic liquid at the extraction stage and separation stage under the optimum conditions.

3.6. Influence of Interference Pigments. Effects of presence of methylene blue on extraction of malachite green by two ionic liquids were observed under the optimized condition. Results showed that the extraction rates of malachite green were more than $95 \%$ in presence of interference pigments, which indicated that these ionic liquids have good selectivity for extracting malachite green.

3.7. Recycling of Ionic Liquid. These ionic liquids can be recycled easily after elution. On addition of $1 \mathrm{~mol} / \mathrm{L} \mathrm{NaOH}$ to the ionic liquids after extraction, malachite green was
TABLE 1: The recovery test results of extraction by IL-1.

\begin{tabular}{lccccc}
\hline Sample & $\begin{array}{c}\text { Origin } \\
(\mathrm{mg} / \mathrm{L})\end{array}$ & $\begin{array}{c}\text { Added } \\
(\mathrm{mg} / \mathrm{L})\end{array}$ & $\begin{array}{c}\text { Found } \\
(\mathrm{mg} / \mathrm{L})\end{array}$ & $\begin{array}{c}\text { Recovery } \\
(\%)\end{array}$ & RSD \\
\hline Water & & 5 & 4.91 & 98.20 & 0.00 \\
sample & 0 & 10 & 9.88 & 98.80 & 0.09 \\
& & 20 & 19.83 & 99.15 & 0.00 \\
\hline Simulation & & 5 & 14.92 & 99.74 & 0.11 \\
water & 9.93 & 10 & 19.91 & 99.74 & 0.00 \\
sample & & 20 & 29.88 & 99.74 & 0.11 \\
\hline
\end{tabular}

TABLE 2: The recovery test results of extraction by IL-2.

\begin{tabular}{lccccc}
\hline Sample & $\begin{array}{c}\text { Origin } \\
(\mathrm{mg} / \mathrm{L})\end{array}$ & $\begin{array}{c}\text { Added } \\
(\mathrm{mg} / \mathrm{L})\end{array}$ & $\begin{array}{c}\text { Found } \\
(\mathrm{mg} / \mathrm{L})\end{array}$ & $\begin{array}{c}\text { Recovery } \\
(\%)\end{array}$ & RSD \\
\hline Water & & 5 & 4.91 & 98.20 & 0.00 \\
sample & 0 & 10 & 9.88 & 98.80 & 0.09 \\
& & 20 & 19.92 & 99.60 & 0.00 \\
\hline Simulation & & 5 & 14.64 & 100.80 & 0.11 \\
water & 9.60 & 10 & 19.59 & 99.90 & 0.00 \\
sample & & 20 & 29.50 & 99.50 & 0.11 \\
\hline
\end{tabular}

removed from the mixture. The recycle yields were $87.1 \%$ and $88.7 \%$ for IL-1 and IL-2, respectively.

3.8. Linearity, Precision, and Accuracy. Under the optimized conditions, the absorbance of malachite green increased linearly in the range of $0-2.5 \mathrm{mg} \cdot \mathrm{L}^{-1}$. The linear regression equation was $A=0.1563 C-0.0023$, and the correlation coefficient $\left(R^{2}\right)$ was 0.9999 . Moreover, the limit of detection was calculated to be $0.044 \mathrm{mg} \cdot \mathrm{L}^{-1}$.

Under the optimal experimental conditions, the relative standard deviation (RSD) of the method was determined by using $5 \mathrm{mg} / \mathrm{L}$ malachite green standard solution for 6 times, with $0.23 \%$ for IL- 1 and $0.37 \%$ for IL-2, respectively. The results showed this method has better accuracy.

Experimental results with the recoveries obtained by the standard addition method are shown in Tables 1 and 2. The recovery results were in the range from $98.20 \%$ to $100.80 \%$. From these results, it was found that the method has good accuracy and it can be used for extraction of malachite green accurately.

\section{Conclusions}

In this study, two thermoregulated ionic liquids were firstly employed as extractants to separate and concentrate malachite green in water. The optimum extraction conditions were achieved with the extraction rate of approximately $100 \%$. Two ionic liquids can be recycled after the elution process, with the recovery higher than $87 \%$. The method provided in this study is not only simple and efficient, selective for extraction of malachite green in the water, but also can avoid the environmental pollution by the extraction agent. 


\section{Data Availability}

The data used to support the findings of this study are available from the corresponding author upon request.

\section{Disclosure}

The funder had no role in study design, data collection and analysis, decision to publish, or preparation of the manuscript.

\section{Conflicts of Interest}

The authors declare that there are no conflicts of interest regarding the publication of this paper.

\section{Acknowledgments}

This research was supported by the Administration Department of Education, Sichuan Province (18ZB0298 and 18ZA0257) and the Scientific Research Fund of Mianyang Teacher's College (MYSY2017QN04).

\section{References}

[1] R. D. Rogers and K. R. Seddon, "Ionic liquids: solvents of the future?," Science, vol. 302, no. 5646, pp. 792-793, 2003.

[2] M. Gharehbaghi and F. Shemirani, "A novel method for dye removal: ionic liquid-based dispersive liquid-liquid extraction (IL-DLLE)," Acta Hydrochimica et Hydrobiologica, vol. 40, no. 3, pp. 290-297, 2012.

[3] Y. C. Fan, M. L. Chen, C. Shentu et al., "Ionic liquids extraction of Para Red and Sudan dyes from chilli powder, chilli oil and food additive combined with high performance liquid chromatography," Analytica Chimica Acta, vol. 650, no. 1, pp. 65-69, 2009.

[4] X. Chen, F. Li, C. Asumana et al., "Extraction of soluble dyes from aqueous solutions with quaternary ammonium-based ionic liquids," Separation and Purification Technology, vol. 106, no. 106, pp. 105-109, 2013.

[5] C. F. Poole and S. K. Poole, "Extraction of organic compounds with room temperature ionic liquids," Journal of Chromatography A, vol. 1217, no. 16, pp. 2268-2286, 2010.

[6] H. Passos, M. G. Freire, and J. A. Coutinho, "Ionic liquid solutions as extractive solvents for value-added compounds from biomass," Green Chemistry, vol. 16, no. 12, p. 4786, 2014.

[7] Q. Zhou, H. Bai, G. Xie et al., "Temperature-controlled ionic liquid dispersive liquid phase micro-extraction," Journal of Chromatography A, vol. 1177, no. 1, pp. 43-49, 2008.

[8] R. Rahnama, N. Mansoursamaei, and M. R. Jamali, "Preconcentration and trace determination of cadmium in spinach and various water samples by temperature-controlled ionic liquid dispersive liquid phase microextraction," Acta Chimica Slovenica, vol. 61, no. 1, pp. 191-196, 2014.

[9] F. Shah, T. G. Kazi, Naeemullah et al., "Temperature controlled ionic liquid-dispersive liquid phase microextraction for determination of trace lead level in blood samples prior to analysis by flame atomic absorption spectrometry with multivariate optimization," Microchemical Journal, vol. 101, no. 3, pp. 5-10, 2012.

[10] K. V. Rao, "Inhibition of DNA synthesis in primary rat hepatocyte cultures by malachite green: a new liver tumor promoter," Toxicology Letters, vol. 81, no. 2-3, pp. 107-113, 1995.

[11] S. Srivastava, R. Sinha, and D. Roy, "Toxicological effects of malachite green," Aquatic Toxicology, vol. 66, no. 3, pp. 319-329, 2004.

[12] I. D. Mall, V. C. Srivastava, N. K. Agarwal et al., "Adsorptive removal of malachite green dye from aqueous solution by bagasse fly ash and activated carbon-kinetic study and equilibrium isotherm analyses," Colloids and Surfaces A Physicochemical and Engineering Aspects, vol. 264, no. 1-3, pp. 17-28, 2005.

[13] S. Chowdhury, R. Mishra, P. Saha et al., "Adsorption thermodynamics, kinetics and isosteric heat of adsorption of malachite green onto chemically modified rice husk," Desalination, vol. 265, no. 1-3, pp. 159-168, 2011.

[14] Z. Zhang, K. Zhou, Y. Bu et al., "Determination of malachite green and crystal violet in environmental water using temperature-controlled ionic liquid dispersive liquid-liquid microextraction coupled with high performance liquid chromatography," Analytical Methods, vol. 4, no. 2, pp. 429-433, 2012.

[15] M. Ramin, F. Khalil, and N. Yousef, "Trace determination of malachite green in water samples using dispersive liquidliquid microextraction coupled with high-performance liquid chromatography-diode array detection," International Journal of Environmental Analytical Chemistry, vol. 92, no. 9, pp. 1026-1035, 2012.

[16] L. Guo, J. Zhang, H. Wei et al., "Nanobeads-based rapid magnetic solid phase extraction of trace amounts of leucomalachite green in Chinese major carps," Talanta, vol. 97, no. 16, p. 336, 2012.

[17] M. J. M. Bueno, S. Herrera, A. Uclés et al., "Determination of malachite green residues in fish using molecularly imprinted solid-phase extraction followed by liquid chromatographylinear ion trap mass spectrometry," Analytica Chimica Acta, vol. 665, no. 1, pp. 47-54, 2010.

[18] J. D. Holbrey, A. E. Visser, S. K. Spear et al., "Mercury (ii) partitioning from aqueous solutions with a new, hydrophobic ethylene-glycol functionalized bis-imidazolium ionic liquid," Green Chemistry, vol. 5, no. 2, pp. 129-135, 2003. 

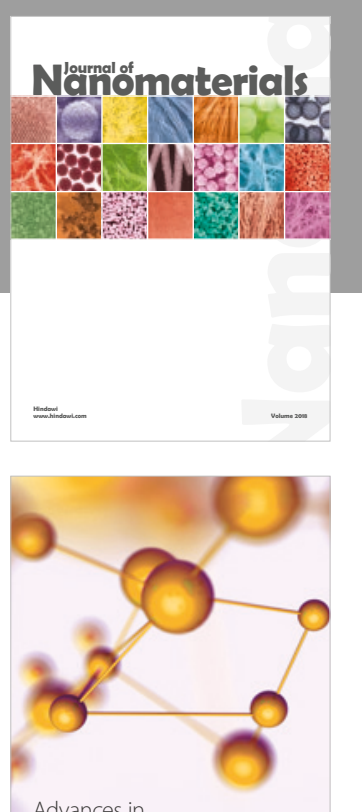

Physical Chemistry
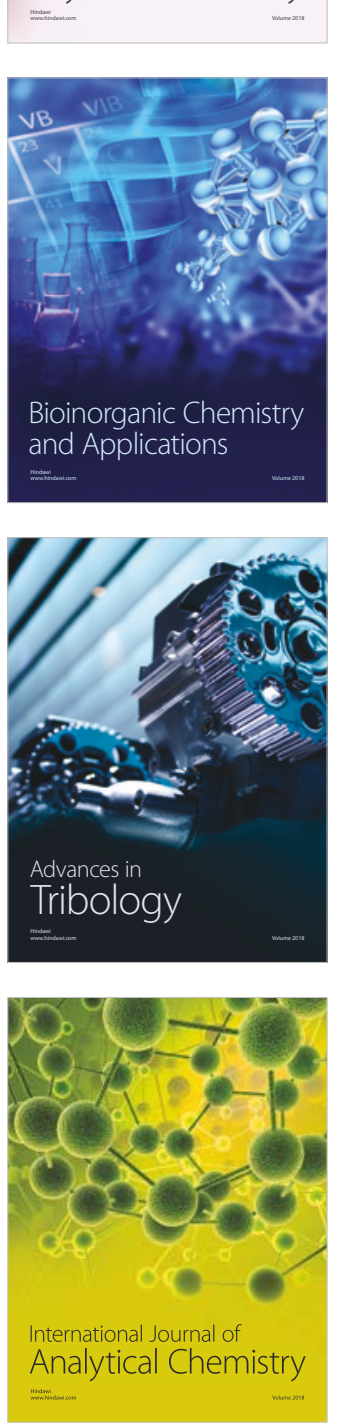

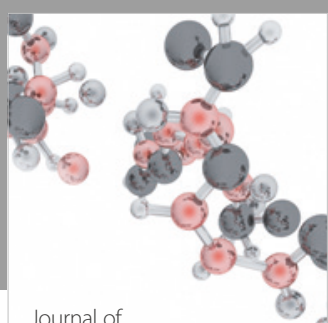

Analytical Methods

in Chemistry

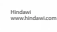

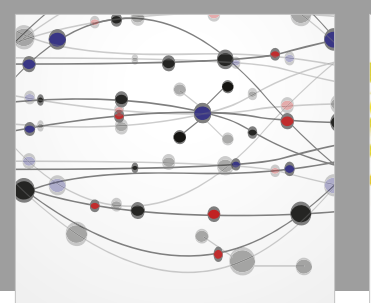

The Scientific World Journal

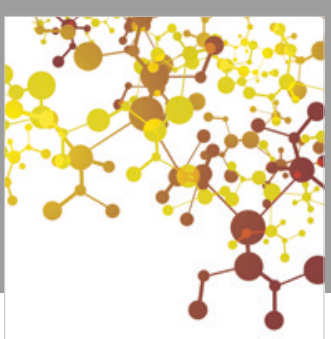

Journal of

Applied Chemistry
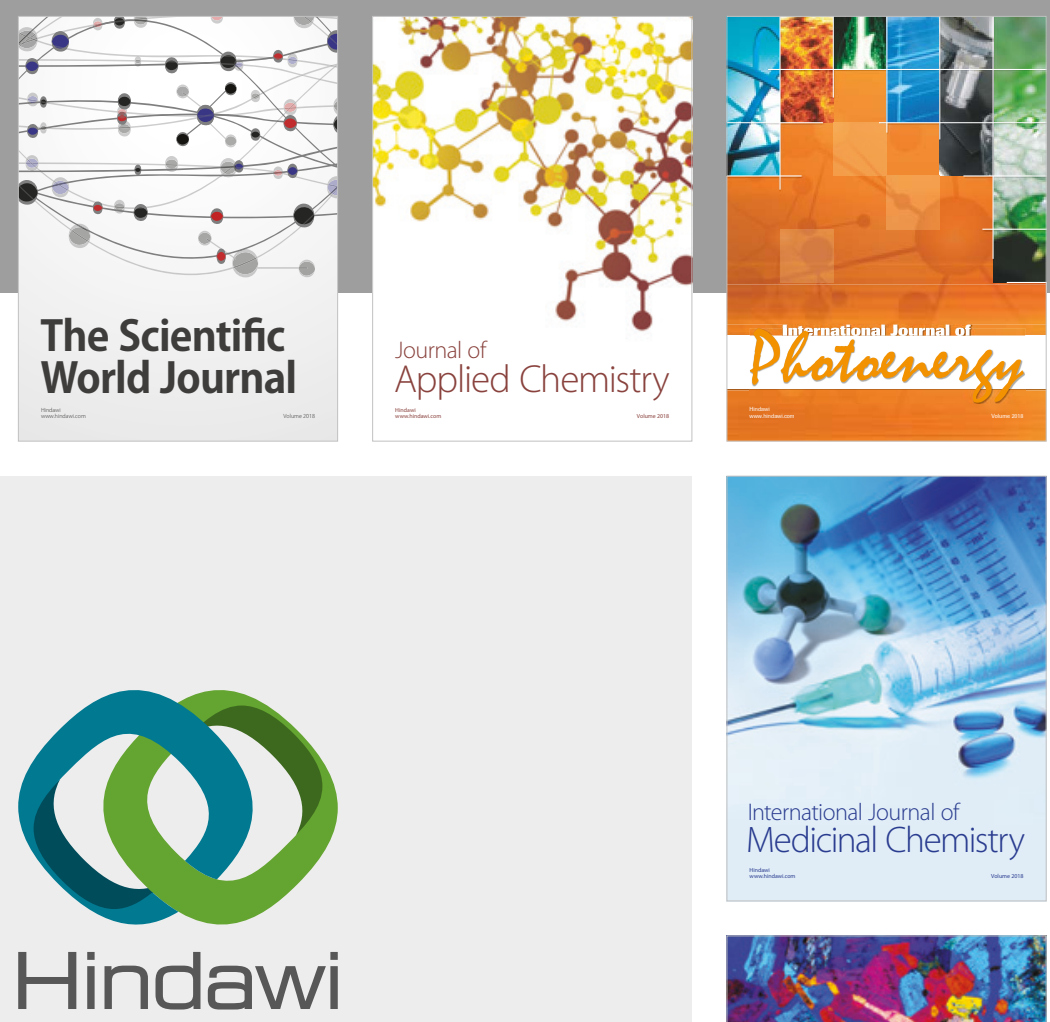

Submit your manuscripts at

www.hindawi.com
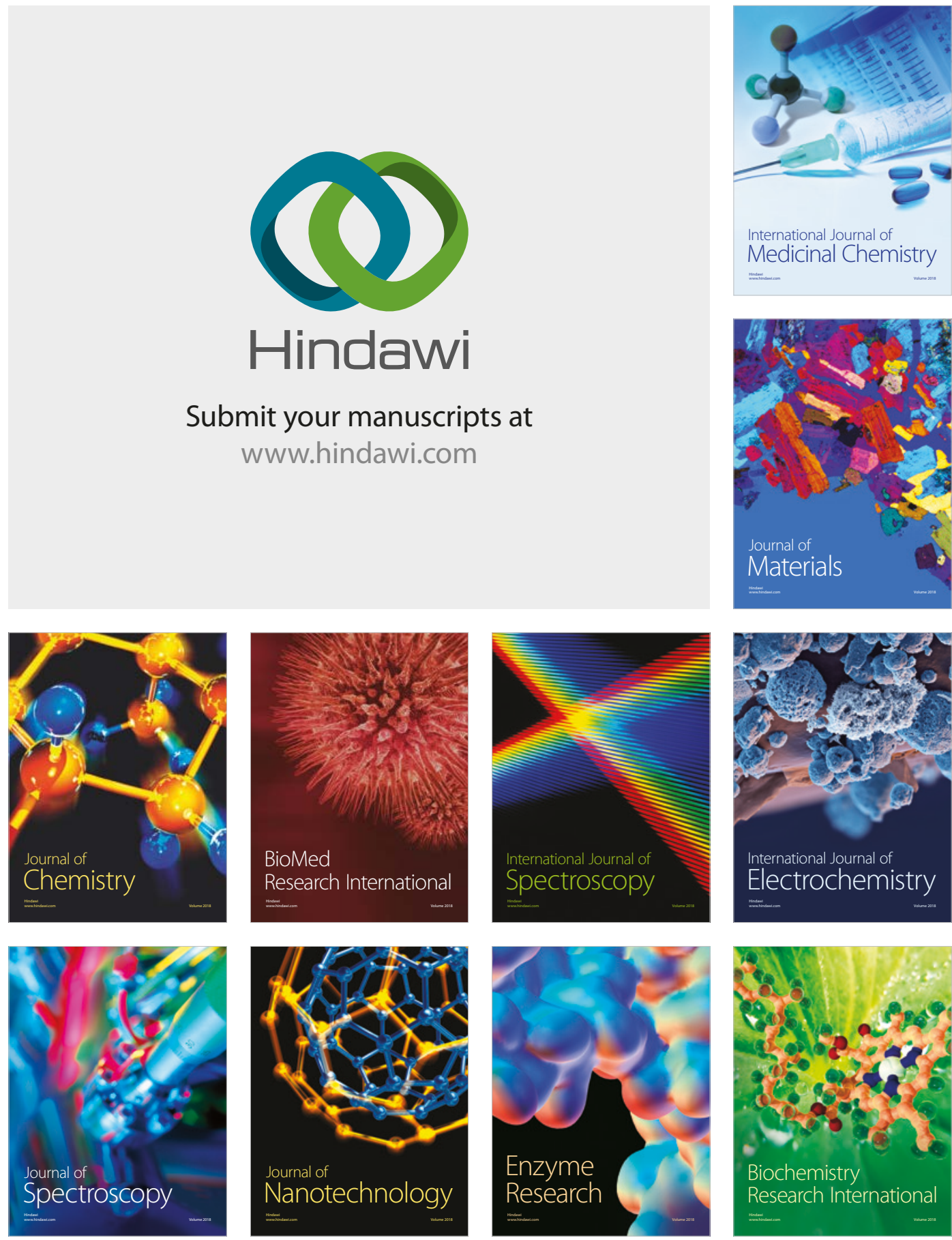
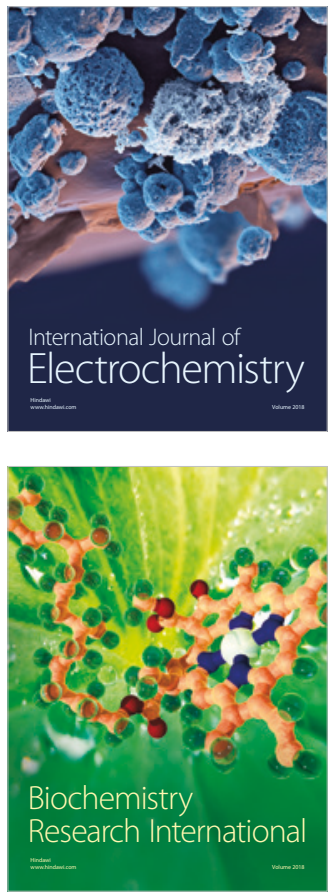